\title{
The Preparation of Spunbonded PA6/PET Segment Bicomponent Fiber
} Yixia Zhao ${ }^{1,2 *}$ and Ya Liu1,2

${ }^{1}$ School of textiles, Tianjin Polytechnic University, Tianjin 300387, China

${ }^{2}$ Key Laboratory of Advanced Textile Composite Materials of Ministry of Education, Tianjin Polytechnic University, Tianjin 300387, China

\begin{abstract}
According to the property study of the polyamide 6 and polyester chips, the process parameters have been confirmed to prepare the spunbonded PA6/PET segmentation bicomponent fiber. Through the cross section study, it was found that the cross section structure was deeply affected by the spinning pressure and temperature of the melt mass. Meanwhile the drawing parameters had important influence on the fineness and strength of the fiber.
\end{abstract}

Keywords: Bicomponent; Spunbond; Fiber; Strength

\section{Introduction}

With the improvement of human's living condition, the high functional fibers were needed in more applications. The natural fibers such as cotton, wool, silk, hemp were applied for the traditional textile products. Especially the silk was the best fiber for apparel with its high drapability, hygroscopicity and flexibility. But the output of silk was limited so it was just suitable for advanced apparels but not for the industrial textiles. Therefore, the synthetic fibre had a huge output, but the fineness of the fiber was 5-6 denier (D), which was much bigger than the diameter of silk. So it showed great difference to the natural fiber in the performance of comfort, softness and aesthetics [1].

The first ultra-fine fiber was made by polyester which treated with aqueous alkali for reduction in Japan. After the chemical finishing, the polyester filament was called artificial silk [2]. It exhibited the similar appearance with silk but the performance was lower than that of silk. The ultra-fine fiber was gradually applied in other fields. The first type of the ultra-fine fiber was made by matrix bicomponent fiber, in which the sea component was dissolved in the specific solution. After the solution was separated from the island component, the ultra-fine fiber was left, the fineness come up to $0.00001 \mathrm{D}$. The fabric which made by the ultra-fine fiber had many advantages such as higher specific surface area, excellent softness and high capacity of dust [3]. The gap between the edges of the finished product provided a great space for accommodate dust and the fabrics were generally used for manufacture high filter material [4].

During the product process, it was not only to keep the normal proportion of the two component, but also to ensure the sea component be dissolved in to the solution during the specify time. However, the recycling of the solution was still a problem and sometimes the sea component was hard to extract from the solution, which raised the cost of the matrix bicomponent fiber. The long cycle of the process and the high cost hindered the development of the matrix ultra-fine bicomponent fiber.

Bicomponent fiber had good performance because of the two components, such as $\mathrm{PP} / \mathrm{PE}$, PET/PA, etc. There were varieties of structures of the bicomponent fibers, such as the sheath-core bicomponent fibers could reduce the energy consumption in the following application process. The side-by-side bicomponent fiber could keep its three-dimensional structure after the hot-through process. Moreover, it could be prepared into a parallel structure of bicomponent fiber, by adjusting the proportion of the components to obtain the fiber with different crimp percentage.

During the study of segmentation bicomponent fiber, the fiber could be split into many parts to produce the ultra-fine fiber. The hollow segmentation bicomponent fiber could be splited into 16 or 32 pies. After hydroentangling, the segments separated from each other and the fineness reached 0.2 0.25D.Compared to the matrix bicomponent fiber, the segment bicomponent fiber splitting process was easier and the hollow structure of the fiber helped reducing the energy consumption of spunlace [5]. The section of the separated fiber was similar to triangle which afforded the fiber great appearance and special function. So the segment bicomponent spunbonded spunlaced microfiber technology became an advanced nonwoven process in the recent years and represented an important direction of the world nonwoven technology development. The spunbonded bicomponent fibers formed the web, then split and entangled by spunlacing process to produce the spunbonded \& spunlaced nonwoven. Due to the high specific area of ultra-fine fiber and the porocity between fibers, the nonwoven fabrics achieved exceptional softness and excellent capability for dust [6-8].

There was only one spunbonded \& spunlaced nonwoven production lines in China, which was located in Jiangxi province. But the performance of the product was not as good as what had expected because of the evenness and low split rate of the bicomponent fibers. So it should be studied more about the process parameters.

In this paper, the hollow segmentation bicomponent fiber and nonwoven fabrics were manufactured by the 30 centimeter wide bicomponent spunbond experimental line in Tianjin Polytechnic University. The melts were spun from the spinneret; they were stretched by the high velocity air in the tube to form the 16 pies hollow bicomponent fiber. The flow chart was shown in Figure 1

*Corresponding author: Yixia zhao, School of textiles, Tianjin Polytechnic University, Tianjin 300387, China, E-mail: carlkarl1234@163.com

Received December 20, 2011; Accepted January 12, 2012; Published January 14, 2012

Citation: Zhao Y, Liu Y (2012) The Preparation of Spunbonded PA6/PET Segment Bicomponent Fiber. J Textile Sci Engg 2:106. doi:10.4172/2165-8064.1000106

Copyright: () 2012 Zhao Y, et al. This is an open-access article distributed under the terms of the Creative Commons Attribution License, which permits unrestricted use, distribution, and reproduction in any medium, provided the original author and source are credited. 
and the schematic of the production line was shown in Figure 2. The relationships between the fiber structure, strength properties and the spinning parameters were analyzed in this paper, which would show significance to the commercial process.

\section{Materials and Methods}

\section{Materials}

The PET and PA6 chips were adopt as raw materials. The PET chips were produced by Sinopec.Ltd of Tianjin, China. The PA6 chips were produced by Longcheng.Ltd of Zhejiang, China. The main performance parameters of the two kinds of chips were shown in Table 1.

\section{Performance test}

The moisture content of the polymer chips was tested by Pressure difference moisture determination device SF-1. The temperature and moisture of cooling air were measured by Temperature sensor TCI-C322-0 and humidity sensor YGM401. The velocity of cooling air was measured by Anemoscope QDE-6. The spinning Temperature was measured by Temperature sensor PT100. The temperature correction was measured by Thermometer TM300 and TM425. Microscope samples were made by Harrington slicer Y172 w. The cross section of the fiber was observed by the Optical microscope VHX-1000.

\section{Results and Discussion}

\section{Thermal analysis of raw materials}

Figure 3 and 4 showed the DSC curves of PA 6 and PET. The heating rate was $10{ }^{\circ} \mathrm{C}$ per min. PA6 sample weight was $10.73 \mathrm{mg}$ and PET sample weight was $15.71 \mathrm{mg}$.

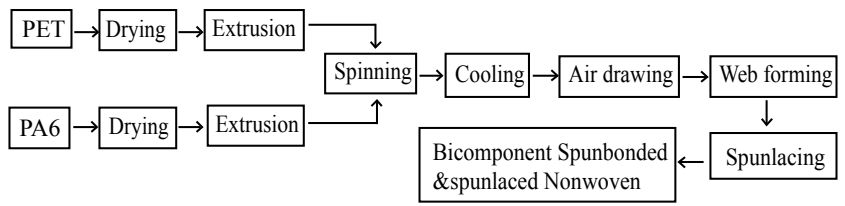

Figure 1: The flow chart of bicomponent spunboned nonwovens.

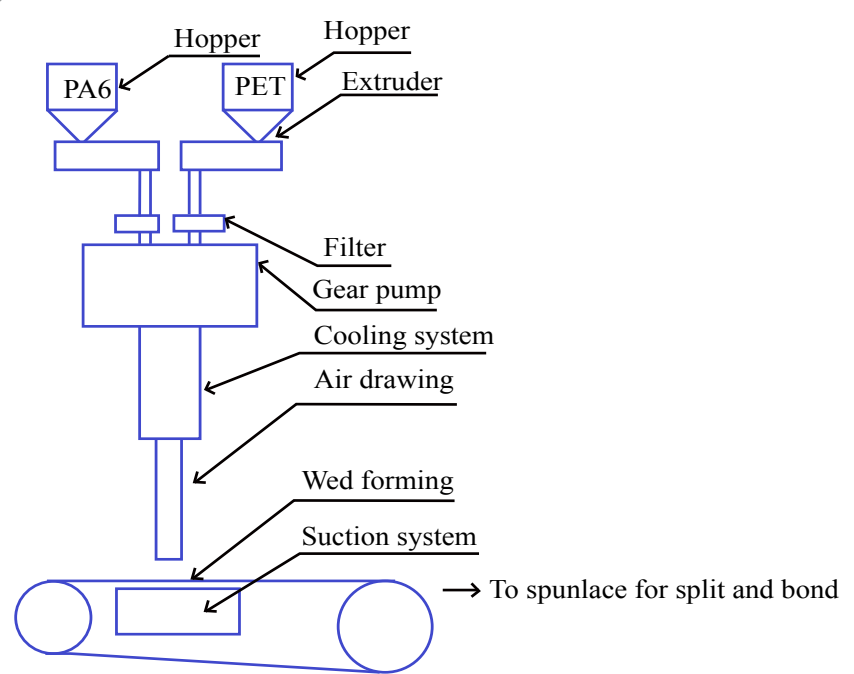

Figure 2: The schematic of bicomponent spunboned nonwovens production line.

\begin{tabular}{|c|c|c|}
\hline Item & PET & PA6 \\
\hline $\begin{array}{c}\text { Intrinsic viscosity } / \mathrm{dL} / \mathrm{g} \\
\text { Relative viscosity }\end{array}$ & $0.65 \pm 0.01$ & - \\
\hline Carboxyl end group $/ \mathrm{meq} / \mathrm{kg}$ & - & $2.4 \pm 0.2$ \\
\hline Triethylene glycol $/ \mathrm{Wt} \%$ & $\leq 27$ & $55-65$ \\
\hline $\mathrm{TiO}_{2} / \mathrm{Wt} \%$ & $0.55-0.76$ & - \\
\hline Water content $/ \mathrm{Wt} \%$ & $0.3-0.5$ & $0.3-0.6$ \\
\hline Density $/ \mathrm{g} / \mathrm{cm}^{3}$ & $\leq 0.4$ & 0.05 \\
\hline
\end{tabular}

Table 1: The main performance parameters of the two kinds of chips.

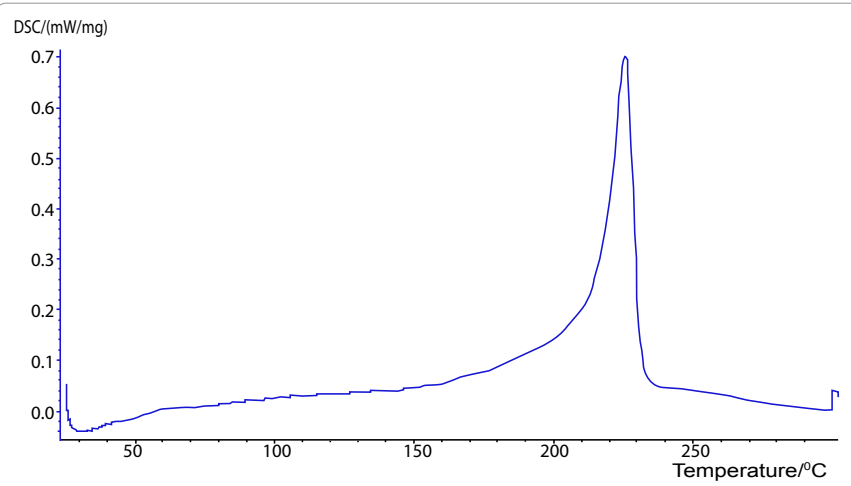

Figure 3: Differential scanning calorimetry curves for PA6.

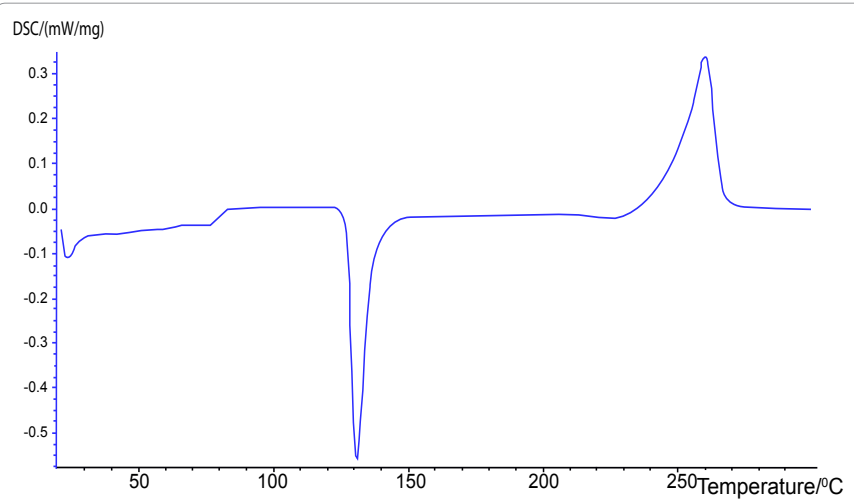

Figure 4: Differential scanning calorimetry curves for PET.

It could be seen from Figure 3 that the melt temperature of PA6 was $216-233^{\circ} \mathrm{C}$ as well as the PET was $248-267^{\circ} \mathrm{C}$.

It showed great difference between the two kinds of chips. The PET was semi-crystalline polymer. And it was easy to found that the first endothermic peak appeared in the range of 127 to $137^{\circ} \mathrm{C}$, which meant that the PET crystallized during this period. Moreover, the melting temperature of PET increased with the raise of crystallinity. So there was an exothermic peak in Figure 4 and the melting temperature became wide.

\section{Production process analysis}

Analysis of drying process: Before the spinning process, the chips must be dried by vacuum rotary drum. Based on the thermal properties of the two kinds of materials, the drying parameters were set according to the DSC test results. 
Since PA6 possessed a good crystallinity there should be no precrystallization process. It led to the simple drying process with the temperature of 75 to $85^{\circ} \mathrm{C}$ for 6-8 hours. Whereas the drying process of PET became more complex for its low crystallinity, so that it required pre-crystallization process before spinning [9]. It was showed in Figure 4 that the PET crystallization temperature was from 127 to $137^{\circ} \mathrm{C}$ and the best crystallization temperature was around $131^{\circ} \mathrm{C}$. So in this study, the pre-crystallized process was at the temperature of $130^{\circ} \mathrm{C}$ for $4-6$ hours and then the chips were heated to $145-155^{\circ} \mathrm{C}$ for $6-8$ hours. After drying, the water content of PET was lower than 30PPM and that of PA6 was less than 200PPM, which would keep the spinning process in a steady state.

Analysis of melt spinning process: After drying process, chips were fed into the screw extruder. The polymer changed from its glassy state to viscous flow in screw extruders. According to the different performances of materials, PA6 chips were fed into screw extruder that the diameter was $45 \mathrm{~mm}$ and length-diameter ratio of 25:1. The PET chips were fed into another screw extruder with the diameter of $55 \mathrm{~mm}$ and length-diameter ratio of 28:1. The two kinds of fondant pasted through the spinning manifold and then traversed into the respective metering pumps [10].

The chips applied in the experiment had great discrepancy in instinct viscosity. In order to keep the volume ratio of the melt in the extrusion process, it should be ensured that the two components had the similar pressure. So it was important to adjust the temperature of spinning manifold to meet with the requirement. PA6 had the high fluidity under the high-temperature conditions especially when the spinning temperature was $50-60^{\circ} \mathrm{C}$ higher than its melting point. Under the same condition, PET had the poor fluidity which would cause problems in its extrusion process. To considerate the thermal properties of the two components, the spinning temperature was set at $293^{\circ} \mathrm{C}$ and the melt pressure was 5.5MPa for PA6 and 6MPa for PET. Figure 5 showed the photos of the spinneret.

The cross section of the bicomponent fiber was shown in Figure 6. It could be seen that the interface of the two components was lucid. There was no evidence to show that the components squeezed by each other. Moreover this segment structure was also beneficial to the fiber splitting process.

During the spinning process, if the melt pressure didn't match with each other when the two components converged in the nozzle aperture, the cross section would appear irregularly shape as showed in Figure 7.

The hollow fiber structure was disappeared in Figure 7a. The PA6 component was pushed to the sides by PET in Figure 7b. The PA6

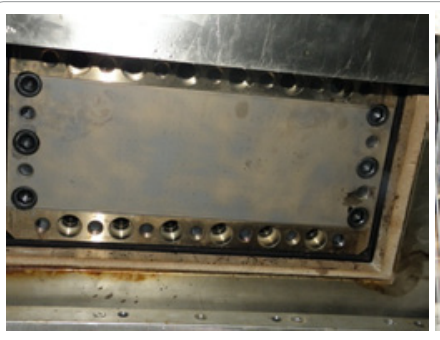

a) Before spinning

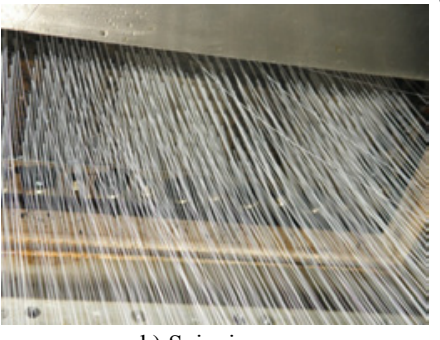

b) Spinning
Figure 5: Photos of the spinneret.

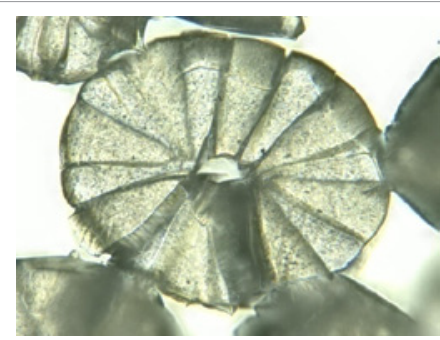

Figure 6: Micrograph of the cross section of bicomponent fiber $(\times 1000)$.
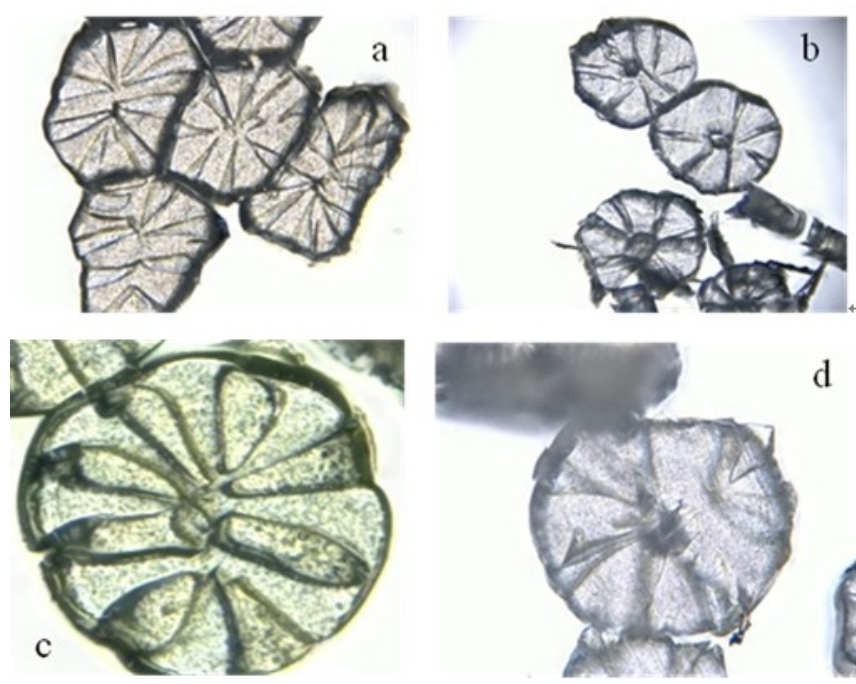

d

Figure 7: Micrograph of irregular cross section of segment bicomponent fiber $(a, b \times 500 ; c, d \times 1000)$.

component was coated by PET component in Figure 7c. The segment structure was almost disappeared in Figure $7 \mathrm{~d}$. However, these cross sections of fiber were not good for fiber splitting.

Analysis of cooling and drawing process: Two kinds of melt converged in the last layer of the spinneret; they were extruded under certain pressure and gravity. The fibers without drawing were known as protofilament. In this research, the cooling air temperature was $17-$ $2^{\circ} \mathrm{C}$, the air pressure was $800 \mathrm{~Pa}$, the speed was $0.45-0.6 \mathrm{~m} / \mathrm{s}$ and the relative humidity is $65-85 \%$. The cooling velocity shouldn't be too quick because it was very important to the structure of the fiber. If the cooling temperature was too low, the rapid solidification was bad for the heat transfer inside the fiber and the two components would split from each other before drawing, which would cause filament broken during the drawing process (Figure 8).

During the drawing process, the fiber was between glassy and highelastic state. There were two types of elongation of the drawn fiber: the elastic recovery and unrecoverable elongation. Also it was the reason why the fiber still had a certain elastic recovery rate. In this study, drawing pipes were used for fiber drawing and the drawing speed was about $8000 \mathrm{~m} / \mathrm{min}$. The protofilament was quickly drawn by the high speed air and it turned into fine fiber through the friction between the air and protofilament. The velocity of the fiber out of the pipe was 3700 $\mathrm{m} / \mathrm{min}$ and the drawing ratio between protofilament and fiber was 10:1 in diameter. 
The hollow segmentation bicomponent fiber of 2.2 2.5D was produced by the bicomponent spunbond experimental line according the above parameters. The fibers were splited through spunlacing and the fineness of the fiber reduced to $0.17-0.23 \mathrm{D}$ which could be called ultra-fine fiber. The strength and breaking elongation of the segment bicomponent fiber were tested by the YG003E single fiber strength tester. The stretch length was $20 \mathrm{~mm}$ and the speed was $20 \mathrm{~mm} / \mathrm{min}$. Before stretching a tension of $0.15 \mathrm{cN}$ was added to the stretching fiber. The testing results showed in Table 2 .

It could be seen from Table 2 that the single bicomponent fiber before splitting had excellent strength about $10 \mathrm{cN}$, and the breaking elongation was less than $60 \%$ which could meet the requirements of the mechanical properties of ultra-fine fibers. The cross section of bicomponent fibre had determined the homogenization in strength and elongation of the fibers [11]. Figure 9 showed the different splitting rate in nonwovens which were made by normal cross section fiber and irregular cross section. And the former was a lot better than the later.

\section{Conclusion}

It was a good method to produce ultra-fine fiber by the segment bicomponent fiber. The material selection was very important. The two components should have sufficiently little adhesion to each other which would lead to the easy split in hydroentangling. Also the two components should have the similar viscosity when they were in melt state and the thermal properties were very important parameter to choose the polymer materials.

The segment bicomponent nowovens was produced under the

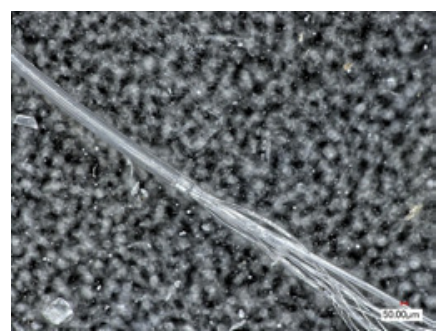

Figure 8: Micrograph of the appearance of the fiber split before drawing $(\times 200)$.

\begin{tabular}{|c|c|c|c|c|}
\hline \multirow{2}{*}{ Sample } & \multicolumn{2}{|c|}{ Normal cross section(A) } & \multicolumn{2}{c|}{ Irregular cross section(B) } \\
\cline { 2 - 5 } & Strength/cN & Elongation /\% & Strength/cN & Elongation /\% \\
\hline Average & 9.86 & 60.7 & 9.55 & 54.9 \\
\hline CV/\% & 6.11 & 8.32 & 34.23 & 52.03 \\
\hline
\end{tabular}

Table 2: The strength and breaking elongation of bicomponent fiber.
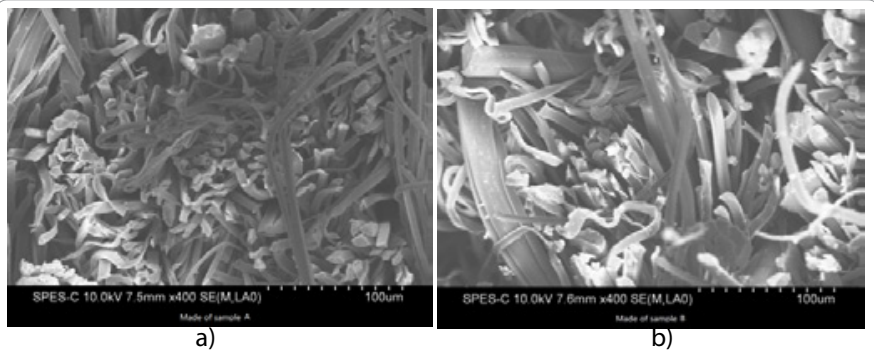

Figure 9: SEM images of the bicomponent nonwovens made by a) normal cross section fiber and b) irregular cross section. conditions as follows: the melting temperature of PET was $290^{\circ} \mathrm{C}$ and the pressure was $6 \mathrm{MPa}$. The melting temperature of PA6 was $260^{\circ} \mathrm{C}$ and the pressure was 5.5MPa. The spinning temperature was $293^{\circ} \mathrm{C}$.

The different proportion of components need different process parameter which related to the melting process parameters, size of spinneret, the melting filter and the air drawing parameters etc. It needs more experiments to certificate the relationship between the parameters and product.

\section{References}

1. Zhang D, Wang $R$ (2007) Superfine fiber production technology and applications. China Textile Press, Beijing.

2. Dong J, Luo H (1996) The technology of synthetic fiber. China Textile Press, Beijing

3. Qi Y, Guo N (2003) Sea-Island Composite Fibre and Its Performance. Technica Textiles 8: 38-41.

4. Gu Y (2011) Market and Technology Development of Microfiber Synthetic Leather. China Textile Leader 3: 85-88.

5. D Wang (2009) Spunlace plus our microfiber spunbond non-woven fabric production line will be put into operation. China Synthetic Fiber Industry 1:29.

6. Zhimin L, Xiaoming Q (2011) Technology and Application of Segmented Pie Bicomponent Spunbonded \& Spunlaced Microfiber. Cotton Textile Technology 7: 65-68.

7. Durany A, Anantharamaiah N, Pourdeyhimi B (2009) High surface area nonwovens via fibrillating spunbonded nonwovens comprising Islands-in-theSea bicomponent filaments: structure - process - property relationships. J Mater Sci 44: 5926-5934.

8. Lu Z, Qian X (2011) Combination Technology of spunbonded \& spunlace. Advanced Materials Research 331: 241-244.

9. Gupta VB, Kothari VK (1997) Manufactured fiber technology 230-300.

10. Irwin M (2007) Hutten Handbook of nonwoven filter media 150-190.

11. Russell SJ (2008) Handbook of Nonwoven 143-203. 